\title{
El ruido popular: derivas poéticas de la variación lingüística en Alfonso Reyes
}

\author{
Graciela SALTO \\ CONICET-Universidad Nacional de La Plata
}

\begin{abstract}
RESUMEN
Entre 1920 y 1940, se observa en la ciudad de Buenos Aires una problematización creciente del papel de la variación lingüística en consonancia con los cambios demográficos y técnicos producidos en ese período y la discusión concomitante sobre el estatuto literario de las prácticas lingüísticas que se consideran "populares”. Se produce, en consecuencia, un desplazamiento desde una valoración romántica y folklórica de las variedades que se escuchan en el español rioplatense hacia el interés de una nueva época por las disrupciones fonéticas producidas por los avances técnicos en el procesamiento del sonido y de la imagen. En este artículo se analiza este desplazamiento en algunos ensayos de Alfonso Reyes escritos durante su estadía en la Argentina, donde el escritor mexicano conceptualiza el ruido dialectal como un epítome de la poesía moderna.
\end{abstract}

Palabras clave: Alfonso Reyes; dialecto; variación lingüística; poesía moderna; lengua popular.

\section{Popular noise: Alfonso Reyes’s poetic drifts of linguistic variation}

\begin{abstract}
Linguistic variation was a growing problem in Buenos Aires between 1920 and 1940; it was in line with demographic and technical changes produced in that period, and the accompanying discussion on the literary status of linguistic "popular" practices. Thus, a shift from a Romantic and Folk assessment of varieties that were heard in the city was produced towards the interest of a new era about phonetic disruptions caused by technical advances in sound and image processing. This paper will analyze these shifts in some trials of Alfonso Reyes written during his stay in Argentina, where the Mexican writer conceptualized dialect noise as an epitome of modern poetry.
\end{abstract}

Keywords: Alfonso Reyes; dialect; linguistic variation; modern poetry; popular language.

SuMARIO: 1.Cada pueblo oye con distinto matiz el mismo ruido. 2.Esa lengua o raro dialecto. 3.Las niñas que nacieron peinadas. 4.Conclusiones.

Una escena de experiencia oral de lo poético, el recitado de una "travesura silábica”, desencadena el conocido ensayo "Las jitanjáforas”, que Alfonso Reyes (1889-1959) publicó por primera vez en 1929, en la revista Libra de Buenos Aires, 
y amplió en ediciones posteriores ${ }^{1}$. En esa escena, una niña de modales agradables y jocosa ingenuidad recita delante de los invitados de su padre, un poeta de renombre, unos versos escritos para la ocasión. No está sola o se supone que no lo está: la acompaña su hermana menor. Podría ser una escena datada en el año o en los meses previos a 1928 y habría ocurrido en la residencia de un diplomático latinoamericano en París. Un lugar y un período donde confluían los estertores de la posguerra con las aspiraciones de una burguesía enriquecida y la ebullición de una estética que ponderaba la novedad y la innovación experimental.

La niña que recita sería la hija mayor del cubano Mariano Brull (1891-956), quien por entonces residía en París junto a su familia y había publicado, un año antes, en 1928, el libro Poemas en menguante. La lectura entusiasta de ese libro es la anécdota que organiza el ensayo de Reyes y también la que promueve una larga exposición genealógica sobre el valor poético del ruido. La trama de vínculos entre uno y otro texto y las relaciones interdiscursivas que lograron convertir a las jitanjáforas en un clásico de las prácticas literarias escolares, mientras un silencioso letargo las arrumbaba en el catálogo de las curiosidades pasadas, es un episodio conocido en la historia literaria latinoamericana ${ }^{2}$.

En este artículo me interesa volver sobre ese texto, sin embargo, para compulsar la validez actual de algunas de sus categorías sobre la función literaria del ruido y sus vínculos con las voces populares ${ }^{3}$, debido a la inusitada y escasamente reconocida actualización de sus postulados en las poéticas que irrumpen en Buenos Aires en la desasosegante década de 1980.

En efecto, en 1981, Arturo Carrera (Buenos Aires, 1948) publica en la revista Xul, signo viejo y nuevo el ensayo "Tejidos esponjosos", reeditado con algunas

\footnotetext{
${ }^{1}$ Para el seguimiento de las circunstancias de producción y publicación de este ensayo, véase el estudio introductorio de Rose Corral (2003) a la edición facsimilar de la Revista Libra.

${ }^{2}$ La relación epistolar y literaria entre Mariano Brull y Alfonso Reyes puede consultarse en el documentado estudio de Alfonso García Morales y también en las cartas transcriptas en la edición de Libra preparada por Rose Corral (2003: 84; 183-5). Respecto de la recepción del ensayo mismo, obsérvese que Reyes anota en su Diario: "Buenos Aires: Éxito de mis jitanjáforas” (1969: 287), pero en una carta a José Ortega y Gasset, se queja de la recepción del texto: "Yo publiqué en Libra una humorada llamada 'Las Jitanjáforas', que en nada difiere de mi habitual humorismo, y que en tiempos más conscientes de la alegría literaria, se hubiera tomado por lo que es: un juego literario. ¿Creerá Ud. que no faltó por ahí alguien que me dijera que había yo escandalizado a muchas personas?” (Reyes, 2003: 165).

${ }^{3}$ Cuando este término o algunas de sus variaciones aparecen en este artículo debería inferirse la tipografía en bastardilla ya que es son acepciones histórica e ideológicamente datadas.
} 
variantes en 1992, 1994 y 1999 con el título "Las niñas que nacieron peinadas". Como se advierte en este último título, el poeta rescata aquella escena de recitación familiar y la ubica, ahora, en el inicio de una serie literaria que extiende sus juegos verbales hasta la poesía concreta. Su bosquejo genealógico incluye los aspectos gráficos y visuales heredados, pero resalta, en particular, los "rumores” y "chillidos pentatónicos" (Carrera, 1981: 29) que se oían en la escena de recitado de "las niñas a cuerda", o de "esas niñas que nacieron peinadas", tal la calificación paródica que titula su ensayo a partir de la segunda edición ${ }^{4}$.

Este rescate irónico y sagaz del "chillido" como elemento fundador de la poesía fonética, más tarde atenuado en "sonido" ${ }^{5}$, y la reubicación contemporánea del olvidado ensayo sobre las jitanjáforas en una serie poco explorada por la crítica literaria, justifican, en consecuencia, una relectura de las categorías conceptuales que entraman los argumentos de Reyes en torno a la noción de "ruido" poético ya que éste es el núcleo conceptual que alcanza renovadas connotaciones en la intervención de Arturo Carrera ${ }^{6}$ y abre un espacio para explorar de nuevo las intersecciones seculares entre oralidad popular y experimentación literaria ${ }^{7}$.

En primer lugar, se abordará en este artículo la temprana articulación entre usos estéticos de los ruidos populares y la experiencia estética moderna, a partir de la lectura de un ensayo sobre la obra de Góngora publicado por Alfonso Reyes en 1911 y un segundo texto que presentó en 1921 con el título "De la lengua vulgar". Luego, se discutirá la categorización estética de algunos de los rasgos etnolingüísticos en el ensayo "Psicología dialectal" de 1924 y, por último, se analizarán los nexos discursivos e intertextuales entre las categorías descriptas en los estudios anteriores y los ensayos producidos durante la estadía de Alfonso

${ }^{4}$ El nuevo título reelabora una imagen pergeñada por Severo Sarduy en "Sobre el castellano en América” (2000: 177).

${ }^{5}$ En ediciones posteriores, se reemplaza "chillidos pentatónicos” por "sonidos pentatónicos”. En 1924, Jorge Luis Borges se había referido a la poesía de Alfonsina Storni como "chillonerías de comadrita”, sin embargo, omito desarrollar esta evocación para evitar digresiones.

${ }^{6}$ En este artículo, me centraré en el problema del ruido pero el ensayo de Carrera señala en la escena de Reyes otros aspectos no menos importantes: "También dieron pie al derroche de tilinguearías placeras e incongruencias eróticas, dignas de un mambeado lenguaraz de Lucio V. Mansilla. ¿Pero por qué abrir, como fuego, un juicio que es caldo de cultivo contra la teoría de los goces?” (Carrera, 1981: 29).

${ }^{7}$ La reedición continua del ensayo de Reyes permite sospechar su vigencia crítica. La última edición conocida es El libro de las jitanjáforas y otros papeles seguidos de retruécanos, sonetórpidos y porras deportivas, selección, prólogo y notas de Adolfo Castañón (Madrid/Frankfurt: Iberoamericana/Vervuert, 2011). 
Reyes en el Hemisferio Sur entre junio de 1927 y diciembre de $1937^{8}$. En uno y otro corpus, se describirá el desplazamiento cognitivo desde la valoración romántica y folklórica de los sonidos ancestrales, de las mínimas unidades fonéticas y sus variables combinatorias en el habla popular, hacia el interés de una nueva época por otros elementos fonéticos que comienzan a oírse merced a los avances técnicos en el procesamiento del sonido y de la imagen y que implican una sustantiva transformación de los problemas inherentes a la práctica intelectual a la vez que se postulan como epítomes de la poesía moderna ${ }^{9}$.

\section{Cada pueblo oye con distinto matiz el mismo ruido}

Alfonso Reyes le dedica algunos estudios tempranos al valor estético del ruido, en consonancia con los intereses del Centro de Estudios Históricos de Madrid, donde colabora entre 1914 y 1924. En esos estudios liminares, centrados en las valencias lingüísticas y folklóricas del habla popular, se hace patente que la voz y el sonido ocupan un lugar destacado en sus indagaciones sobre los fundamentos de la literatura moderna.

En el ensayo "Sobre la estética de Góngora” (1911), Reyes se explaya sobre una de las relaciones estéticas que mayor expansión alcanzará en sus estudios posteriores: "el [poeta] gongorino [...] necesita ir a los atributos de color y de ruido que desprende de los objetos. Como ruido y como color se le acerca el mundo, y como ruido y como color lo traduce" (Reyes 1911: 74; el énfasis no está en el original). La insistencia en el efecto literario de estos estímulos sonoros y visuales se especifica, avanzado el ensayo, como un rasgo metonímico que signaría el conjunto de la poesía española:

Muy española tendencia, por otra parte, es la de Góngora [...] Parece, a veces, que los poetas españoles sólo se guiaran por un ruido interno, por una armonía irresoluta que les zumba al oído incesantemente, hasta que no la vierten y la traducen en palabras. (Reyes 1911: 83; el énfasis no está en el original)

\footnotetext{
${ }^{8}$ Para un detalle específico de las funciones y las actividades cumplidas por Reyes durante su estadía diplomática así como sobre la repercusión de su figura entre los escritores argentinos, véanse los testimonios periodísticos recopilados por Robledo Rincón (1998). Sobre sus ideas y reflexiones en torno a este período, puede consultarse su Diario (Reyes, 1969)

${ }^{9}$ Las primeras hipótesis de este trabajo fueron leídas en las Jornadas Andinas de Literatura Latinoamericana realizadas en Nitéroi en 2010 (JALLA Brasil 2010) y, unos meses más tarde, las presenté en la conferencia inaugural del IV Encuentro de la Red de Docencia e Investigación en Literatura Latinoamericana Katatay que se realizó en La Falda, Argentina, entre el 3 y el 5 de diciembre del mismo año.
} 
La interrelación productiva de los atributos de color y de ruido así como el zumbido poético del final recuerdan los trazos más visibles de la escena descripta al inicio de este artículo, prefigurada aquí en sus rasgos principales: una tenue e intrincada trama parece unir, en efecto, la "armonía irresoluta" de los poetas gongorinos con los chillidos de la niña recitando.

En el mismo período en que Reyes escribe este ensayo, la potencialidad estética del ruido era exhibida también, aunque con disímil valor, por varios grupos vanguardistas y, en especial, por los futuristas italianos, quienes celebrarían en 1916 la publicación de $L$ 'Arte dei Rumori de Luigi Russolo ${ }^{10}$. Reyes estaba al tanto de las propuestas que exaltaban los ruidos emanados de las máquinas, pero mantenía una distancia recelosa de los experimentos sonoros de sus coetáneos en quienes advertía los riesgos de una "decadencia estética" surgida de los estertores de la guerra (1918: $463)^{11}$. En la misma etapa, en cambio, concentra sus esfuerzos teóricos en dilucidar las relaciones de otros ruidos: aquellos que surgen de los usos populares de la lengua y que permiten atisbar la potencialidad estética de las variantes dialectales. Como varios de sus coetáneos, encontraba allí un repositorio de originalidad que podía revitalizar el anquilosamiento de la lengua literaria aunque con otras consecuencias estéticas.

En 1916, se había publicado en México, por ejemplo, el ensayo de Manuel Gamio, Forjando patria (pro nacionalismo), donde se exhiben las búsquedas de los letrados revolucionarios por distinguir entre usos nacionales de la lengua y de la literatura en un período de esclarecimiento sobre los límites étnicos y culturales de la nación en ciernes. La tesis que sostiene Gamio encuentra en la población indígena y en sus usos lingüísticos y artísticos algunos de los elementos centrales en la configuración de la cultura mexicana moderna y su postura contrasta con la valoración esteticista de Reyes, quien pondera en las voces y el murmullo del pueblo más los rasgos acústicos que los étnicos ${ }^{12}$. Es sólo un ejemplo de los muchos ensayos que, por esos años, abordan el valor de lo popular en el diseño de las

${ }^{10}$ En un ensayo publicado en 1912, “Los desaparecidos”, puede advertirse, por ejemplo, su alusión irónica a las búsquedas cientificistas de los italianos: "Ignoro si la poesía futurista habrá pensado ya en aprovechar las emociones de la estadística. Marinetti debiera considerarlo con detenimiento” (Reyes, 1912: 243).

${ }^{11}$ La función de los avances tecnológicos en la articulación de los movimientos de vanguardia ha sido descripta por varios estudiosos del periodo. Andrea Huyssen hizo de esta constatación una de sus hipótesis más importantes: "Ningún otro factor ha influido tanto en la emergencia del nuevo arte de vanguardia como la tecnología (2006: 29). En el caso del campo literario argentino, Beatriz Sarlo (1992) dedicó también un estudio muy relevante al análisis de la articulación entre avances técnicos y producción literaria.

${ }^{12}$ Varias décadas después, Ángel Rama (1983) analiza la obliteración de las voces y los ruidos de vastos sectores sociales desde la época virreinal. 
políticas públicas y que, por diferentes vías, promueven la revisión de las imágenes sobre la cultura y la lengua popular que habían incidido en la formación de los imaginarios nacionales ${ }^{13}$. La extraterritorialidad de Reyes no le impide seguir de cerca estos análisis ya que sigue con avidez las discusiones que se generan en su país de origen del mismo modo que las ideas que circulan en sus lugares de residencia.

En un ensayo de 1921, "De la lengua vulgar”, y según la impronta de los diálogos renacentistas sobre este tópico ${ }^{14}$, Reyes despliega también sus intuiciones sobre la importancia de los usos cotidianos de la voz a partir de dos parámetros relevantes: la pronunciación, donde cree descubrir "los movimientos del lenguaje vivo", y los errores del vulgo, los dislates, donde encuentra prefigurados los giros cultos del futuro (Reyes, 1921: 141-146). En la intersección de estas dos variables, el sonido, por un lado, y las emisiones que la lingüística posterior llamaría agramaticales, por otro, ubica una potencia creativa a la que suma además un componente popular: "sólo el populacho tiene el valor de innovar" (1921: 142) y otro, dialectal: "cada pueblo oye el mismo ruido de distinta manera, con un coro de matices étnicos distintos" (1921: 147) ${ }^{15}$.

En estos bosquejos iniciales, se advierte que el ruido preexiste al habla, se ubica en un lugar no definido, inquietante, y, desde allí acecha a los poetas, con "una armonía irresoluta que les zumba al oído” (Reyes, 1911: 83) y desencadena al menos dos procesos interrelacionados: en el caso gongorino, un regodeo en la perífrasis que, según Reyes, es "tendencia, o mejor obsesión, por ir caminando sobre las puras cualidades de color y de sonoridad que tienen las cosas” (74) y, por otro, una escucha que difiere, según los rasgos étnicos de los hablantes y produce emisiones orales diferenciadas, dialectales: un "coro de matices étnicos" (1921: 147). Perífrasis verbal, exceso fónico y diferencia étnica se imbrican así en un esquema conceptual que se asienta sobre la escucha de ruidos que potencian la productividad lingüística popular y en el desdén por la normativa:

${ }^{13}$ La discusión sobre el nacionalismo cultural alcanzó en México su punto de más álgido en una recordada polémica de 1932 protagonizada, entre otros, por Alfonso Reyes (Houvenaghel, 2002; Rangel Guerra, 2005).

14 La argumentación sigue, en gran medida, el famoso Diálogo de la lengua de Juan Valdés impreso en 1777, aunque datado alrededor de 1535, y el canónico De vulgari eloquentia (Tratado de la lengua vulgar) de Dante Alighieri escrito entre 1304 y 1307, aproximadamente.

${ }^{15}$ La actualización del topos renacentista de la autenticidad del lenguaje popular se hace patente en el siguiente fragmento: "El don primitivo de plasmar la lengua sólo el pueblo lo posee. En él la lengua crece y fruta cual en su terreno las plantas, al paso que en los libros está como desecada” (Reyes, 1921: 142). 
... sólo el populacho tiene el valor de innovar, de pronunciar mal, de ir haciendo mudarse los giros y las expresiones [...] Están demasiado vivas en ellos las fuerzas humanas. Les sobra algo de la energía creadora del tipo. Su andar tiende a la danza y su hablar tiende al caló. Estos son los padres del idioma. (Reyes, 1921: 142-7)

Esta insistencia en que la iniciativa del cambio idiomático y las posibilidades de innovación residen en los ruidos escuchados por el pueblo y que son procesados de modo aleatorio merced a un vitalismo intrínseco a su falta de conocimientos y a su exaltación del goce corporal, confluye a su vez con otro argumento esbozado en ese mismo ensayo en torno de la irracionalidad o el paralogismo intrínseco a la lengua $^{16}$. Reyes seguía de cerca, por entonces, las ideas de Henri-Louis Bergson ${ }^{17} \mathrm{y}$ de otros irracionalistas que compartían sus hipótesis sobre la falta de logicidad de las relaciones lingüísticas y también del proceso creativo en su conjunto. Dos años antes, en 1909, había publicado el primer estudio sobre la obra de Stéphane Mallarmé que se conoce en español y exhortaba allí al sinceramiento de los poetas acerca de los elementos irracionales que insuflan el acto de creación:

que respondan los poetas, y digan si no es tan intempestivamente como llegan a la conciencia objetos e imágenes, en el calor impaciente de crear. Estas irrupciones de imágenes y pensamientos, como obedecen a una cerebración casi automática y personalísima a todas luces, escapan a la previsión racional, y en verdad, sólo se explican dentro de la mente quien las percibe, y por el solo hecho de su aparición. (Reyes, 1909: 92)

Reyes comienza así a operar con dos categorías conceptuales, automatismo y ruido, que tenían ya una validación específica en el ámbito de los procedimientos y de los postulados de las vanguardias, sobre todo europeas, y que los jóvenes latinoamericanos apenas si comenzaban a explorar. Si bien sus intervenciones recuperan algunos rasgos de esas lecturas de época, las insertan más bien en un itinerario de lecturas específico que, en primer lugar, fija su atención sobre la fecundidad creativa de lo popular, en consonancia con su interés filológico por

${ }^{16}$ Cfr. "El idioma y la lógica son cosas diversas y aun opuestas. Dicen los técnicos que las transformaciones del sentido de las palabras se operan según figuras llamadas catacresis, sinécdoque, metáfora y otras, las cuales precisamente consisten en poner de relieve una cualidad especial del objeto a expensas de las demás; es decir: con desdén para la lógica. Y añaden que las transformaciones de los idiomas reposan sobre el razonamiento oblicuo; por manera que el lenguaje, este gran fenómeno humano, tiene por principio un paralogismo" (Reyes, 1921: 142; el énfasis consta en el original).

${ }^{17}$ Se habían encontrado durante su estadía en Madrid y, de esa época, data el artículo de Reyes, “La sonrisa”, que dialoga con el por entonces ya célebre Le rire (1899) de Bergson. 
dilucidar los juegos verbales gongorinos y, en segundo lugar, vincula la opacidad representativa del lenguaje barroco con la inefabilidad mallarmeana ${ }^{18}$.

En un ensayo publicado poco tiempo después, "Psicología dialectal”, de 1924, suma otro elemento que complejiza este esquema de valoración del ruido poético: subraya que es en "aquellos cristales de la lengua -frases hechas, monedas de la expresión corriente- que han perdido su equivalencia o nunca la tuvieron en el seno de la lengua madre" donde se encuentra la posibilidad de "ir construyendo una teoría de nuestra sensibilidad, diferente, americana...” (Reyes, 1924: 339-40). Pocas líneas antes, confesaba: "Yo siento que siento en una lengua levemente distinta de la peninsular. En esta levedad del matiz está el conflicto".

La ubicación del conflicto por la lengua en la experiencia de la levedad y del sentir, precisamente donde se instala -según puede leerse desde algunas teorías contemporáneas, como la de Gilles Deleuze - la experiencia de lo literario y, al mismo tiempo, la categorización de ese conflicto cultural como "desviación dialectal” es un avance significativo de sus presupuestos teóricos en torno de la inefabilidad del lenguaje. Por un lado, el dialecto es equiparado a los "cristales de la lengua”, a los restos, excedentes, residuos fonéticos y léxicos donde es posible leer los indicios de la literatura por venir. Por otro, como un núcleo generador de tradiciones en el que Reyes encuentra fundamentos para "ir construyendo una teoría de nuestra sensibilidad” y también un lugar donde anclar el conflicto cultural y político que surge por "la levedad del matiz". Es en la diferencia dialectal, en suma, donde el intelectual mexicano comienza a cotejar los márgenes estrechos de la norma peninsular que tanto develaba a sus compañeros del Centro de Estudios Históricos de Madrid ${ }^{19}$ y abre la posibilidad de explorar una conceptualización más moderna de la lengua popular y más adecuada a las espectaculares transformaciones del período de entreguerras.

Se observa así como el acento puesto sobre las voces emanadas de un ruido inicial que se oye y se plasma de diferentes modos, cristales sin equivalencia gramatical pero de uso cotidiano, popular, facilita en su teoría el pasaje desde el inmovilismo arcaizante de una oralidad folklórica, fijada en usos estereotipados, hacia la productividad y la mutabilidad de las voces populares en la teoría moderna donde la aleatoriedad de la experiencia de la escucha y de la lectura define, en gran

${ }^{18}$ Cfr. la atinada observación de Hans Robert Jauss: “La oscura lírica de Mallarmé y de su escuela fue la que preparó el terreno para la vuelta a la poesía barroca, desde hacía mucho tiempo ya no apreciada, y por consiguiente, olvidada, y en especial para la reinterpretación filológica y el ‘renacimiento’ de Góngora” (Jauss, 1976: 193).

${ }^{19}$ Ignacio Sánchez Prado (2009) ha reclamado, en un estudio reciente, un análisis más específico del mentado hispanismo de Reyes para poder advertir éstas y otras diferencias con la escuela filológica española. 
medida, el valor que se les asigne. Esta es una idea que coincide, en parte, con las consideraciones universalistas del Congreso sobre artes populares realizado en 1928 en Praga bajo el auspicio del Instituto Internacional de Cooperación Intelectual. Frente a la encerrona del nacionalismo que, por esos años, intentaba reducir el arte y los usos populares a una vinculación estrecha con lo local y en la cual Reyes es muy posible que encontrara ecos de la situación mexicana, el Congreso postuló, en cambio, el valor regional y transnacional de lo popular y encareció un estudio científico de sus prácticas y significaciones ${ }^{20}$. En concomitancia con esta tendencia pueden leerse las hipótesis de Reyes sobre el valor diferencial de la voces dialectales: donde la mayoría de los gramáticos y filólogos encontraban meros fraseos y dichos de valor local, Reyes descubre, en cambio, un lugar para anclar la construcción de "una teoría de nuestra sensibilidad (1924: 339) y, pocos años después, un esbozo de su teoría poética sobre "Las Jitanjáforas”. Su estetización del ruido popular contrasta, así, con algunas de las posturas más extendidas en la época y abre, en cambio, un espacio para analizar las intersecciones y disrupciones entre culturales populares y estrategias modernizadoras. Por un lado, enfrenta la frecuente constricción de lo popular a lo étnico, tal como se vislumbraba en México y en otras regiones del continente americano; por otro, atisba los riesgos implícitos en la exaltación futurista de los ruidos tecnológicos tan frecuente en los nacionalismos europeos.

\section{Esa lengua o raro dialecto}

Entre 1927 y 1937, Reyes se instaló alternativamente en Buenos Aires y Río de Janeiro, en un período de peculiar religación y fluidez de contactos que le permitió discutir, en un entorno descentrado, algunas de las categorías políticas y culturales que tensionaban el espacio intelectual mexicano. A partir de su llegada, testimoniada en numerosos comentarios sobre su viaje desde Madrid hasta Sudamérica y en varios homenajes registrados en los diarios de la época, se advierte la posición relevante que ocupó entre los jóvenes escritores de estas dos ciudades. A Buenos Aires, llegó en un período de extraordinaria vinculación intercontinental debido a las migraciones de la posguerra y, también, de un notable dinamismo cultural y editorial propulsado por una prensa en acelerado proceso de expansión y

${ }^{20}$ Cfr. "Les influences réciproques des arts populaires s'étendant au delà des frontières politiques, permettaient de reconnaître, à la lumière de ce rapprochement international, des éléments essentiels de la communauté humaine, traduits par un motif décoratif, un thème musical ou un pas de danse. Ces données objectives, scientifiquement considérées, illustraient des pensées qui constituent l'idéal même de la Société des Nations” (Dupierreux, 1929: 15). 
un conjunto de experiencias estéticas que disputaban su lugar entre las vanguardias del continente.

En esta coyuntura, las ideas de Reyes sobre el valor de la "desviación dialectal" se compulsaron con la de varios escritores y grupos locales, entre quienes los usos de la lengua habían adquirido, desde hacía varios años, un estatuto problemático (Schwartz, 2002; Gelado, 2008; Di Tullio, 2009) ${ }^{21}$. Tanto en la revista Libra y en los Cuadernos del Plata editados por él en Buenos Aires o en el correo literario Monterrey publicado desde Río de Janeiro se advierten las tensiones producidas por el encuentro con distintas variedades y modulaciones de las lenguas y de las culturas. En cierto sentido, por ejemplo, las ideas de Reyes comparten la conceptualización del sonido que subyace en la colección del Folklore argentino recogida por Robert Lehmann-Nitsche en 1905. Ese repositorio de voces populares, editado por Miguel García y Gloria Chicote en 2008, demuestra los peculiares intereses del antropólogo alemán por registrar e identificar usos alternativos de la voz: un interés que también Marcel Duchamp pudo atisbar durante su viaje a la ciudad en 1918 (Antelo, 2006: 72). Otras vinculaciones se leen en la profusa correspondencia que Reyes intercambió con intelectuales de ambos países durante varios años y en las entradas de su Diario, donde se entrevén sus controversias literarias durante la estadía en el Hemisferio Sur y su creciente interés por las consecuencias estéticas de las innovaciones que se estaban dando en el ámbito de las comunicaciones.

En su Diario puede seguirse el itinerario de lecturas y de proyectos intelectuales de este período, a pesar de los innumerables distractores con que las tareas diplomáticas amenazaban su vida de escritor (Reyes, 1969: 44-55) ${ }^{22}$. Se destaca la edición de sus Cuestiones gongorinas, que la editorial Espasa-Calpe publicó en Madrid en 1928, y un ensayo que habría preparado durante una breve estadía en la ciudad de Tandil y al que alude en su diario aunque no existe registro posterior de su publicación: "En el harem del idioma: de la sintaxis de la jeroglífica y de la fonética” (1969: 209). En el mismo año 1928 consigna, además, entre innumerables conferencias y contribuciones solicitadas por diversas instituciones educativas y agrupaciones editoriales, la preparación de un extenso estudio sobre Juan Ruiz de

${ }^{21}$ Sólo como ejemplos del clima de época, recuérdese que, en 1928, Jorge Luis Borges, uno de los jóvenes que se vinculó con Reyes en el momento de su llegada, publicaría El idioma de los argentinos. Un año después, Roberto Arlt incluiría también sus reflexiones sobre el lenguaje en una de sus Aguafuertes porteñas. Para un detalle de estas inquietudes, véanse Armus (1990); Sarlo (1992), entre otros.

${ }^{22}$ Cfr. sus reflexiones en la entrada del 12 de septiembre de su Diario: "Me es materialmente imposible seguir el paso de mi vida. No puedo dejar constancia aquí de nada. [...] ¿De qué puede servir vivir así, dándose todo a lo accesorio? No escribo, no leo, no pienso. ¡Ay de mi vida!” (Reyes, 1969: 205). 
Alarcón (225), la reedición de Culto a Mallarmé (231-3) y la preparación de los célebres y, finalmente truncos, Cuadernos del Plata (234-6) ${ }^{23}$. En 1929, agrega la preparación de un anecdotario y distintas traducciones de Mallarmé; continúa con la edición de los Cuadernos del Plata y con la idea de "hacer una teoría de la poesía" (249) que, finalmente, se publica ese año en Libra con el título de "Las Jitanjáforas" (2003: 273; 279; 287).

La enumeración de estas lecturas, escrituras y proyectos editoriales, permite atisbar, más allá del desbordante trabajo de un escritor devenido diplomático, la persistencia de un interés particular por el Barroco, tanto en su versión gongorina como en la del Barroco de Indias, y su coexistencia con el afán exploratorio de la poética de Mallarmé y de las producciones de los jóvenes escritores argentinos y mexicanos. Este entramado de intereses, en apariencia disímiles, se articula, sin embargo, en torno de la relevancia que adquieren los usos populares de la lengua en sus postulados teóricos. Su reivindicación temprana de los "atributos de color y de ruido" en la poética gongorina marca, de hecho, un punto de inflexión en las lecturas del Barroco que no todos los críticos han señalado con precisión.

Irlemar Chiampi bosqueja, por ejemplo, dos ciclos y reciclajes que habrían insertado el Barroco en la modernidad latinoamericana: sitúa el primero en las lecturas del modernismo dariano y el segundo, en la apropiación tópica de las estéticas premodernas por parte de algunos vanguardismos, como el ultraísta de Jorge Luis Borges (Chiampi, 2000: 19-20). Según esta postura, se habría producido un redescubrimiento de la metáfora gongorina "en el contexto crítico europeo postsimbolista, que inicia la recuperación estética de Góngora, mediante el paralelo con Mallarmé, tras el purgatorio de tres siglos” (Chiampi, 2000: 20). La lectura de Chiampi soslaya que, hasta donde se sabe, el primer estudio sobre Mallarmé publicado en español es el de Reyes, en 1909, y que el análisis de la potencialidad de la metáfora gongorina para la poesía moderna es también una tesis estrechamente vinculada con los estudios sobre Góngora que publicó en 1911. Es decir, la posibilidad de leer a Góngora a partir del arsenal teórico aportado por las reflexiones de Mallarmé sobre la opacidad del lenguaje es, en gran medida, un aporte de las hipótesis de Alfonso Reyes sobre la irracionalidad y el automatismo en

${ }^{23}$ El detalle de los escritores y pintores que desea ver incluidos en esta publicación permite reconstruir el entretejido de sus preferencias estéticas: "En los Cuadernos del Plata sueño los nombres siguientes: Pedro Henríquez Ureña / Victoria Ocampo (parece que tiene una traducción de Daisy Ashford) / J. Luis Borges / Diego Rivera / Ricardo Güiraldes (inéditos) / Olivero Girondo / Fnco. Luis Bernárdez / Sergio Piñera, hijo (inédito) / ¿González Lanuza? / Xul Solar / Ricardo Molinari / ¿Eg Bullrich? / Genero Estrada / Antonio Castro Leal / Julio Torri. Antología yanqui traducida, por los chicos mexicanos. Los que llevan más son, además, dibujantes. Y hay también los dibujantes siguientes: Norah Borges / Pettoruti / Silvina Ocampo / Orozco / C. González, etc.” (Reyes, 1969: 235-6). 
la percepción poética de los ruidos populares. En esta línea de apreciación, Aurora Egido exalta, en cambio, los aportes del mexicano a la lectura de Góngora en clave mallarmeana:

[El estudio de Reyes] ofrecía así la especie de un Góngora que brillaba más por las palabras que por el contenido, amigo de la perífrasis y de la huida del lugar común, y que excedía a todos en las formas visuales y auditivas, pero también en su vitalismo y acción, como digno heredero de las propuestas mallarmeanas.

Todo ello era inseparable de la estética que el mismo Reyes abordaba en ese libro de 1911, donde analizó, en la poesía de Mallarmé, el problema de la inefabilidad del lenguaje, incapaz de exprimir o expresar los conceptos. (Egido 2009: 98)

En este marco de intersecciones entre los juegos verbales del Barroco y los postulados críticos más recientes sobre la poesía, Reyes escribe en Buenos Aires su propia "teoría de la poesía" (Reyes, 1969: 249) en la que eleva el ruido irracional, explorado en los estudios de la etapa madrileña, a categoría poética:

¡La verdad es que, en el taller del cerebro, se amontonan tantas astillas! De tiempo en tiempo, salen, a escobazos, por la puerta de las palabras: pedazos de frases que no parecen de este mundo; y otras veces, meros impulsos rítmicos, necesidad de oír ciertos ruidos y ciertas pausas que -después de todo--- son como la anatomía visible del poema”. (2003: 7; el énfasis no consta en el original)

Pocas líneas más adelante habla de "obsesiones auditivas” y concluye: "Soy completamente incapaz de decir lo que esto significa [se refiere a los estribillos caracterizados como ruidos], ni de dónde salió esta lengua o raro dialecto" (2003: 7; el énfasis no está en el original). Es notorio, entonces, que tanto en el estudio de 1924 sobre la "Psicología dialectal", como en el ensayo sobre "Las jitanjáforas" de 1929, sólo rescata, del inmenso repertorio de rasgos lingüísticos disponibles, aquellos elementos acústicos indeterminados que propician una escucha aleatoria y que escapan a los controles de la gramaticalidad. El sonido, el ruido, la voz engarzan, desde ese período, un conjunto de imágenes que van confluyendo en una conceptualización sobre la poética e, incluso, sobre el arte en general, basada en el ruido:

Hay horas en que las palabras mismas se alejan, dejando en su lugar unas sombras que las imitan. Los ruidos articulados [...] acuden a beber un poco de vida, y se agarran a nuestra pulpa espiritual con una voracidad de sanguijuelas. Sedientas formas transparentes -como las evocadas por Odiseo entre los cimerianos - rondan nuestro pozo de sangre y emiten voces en sordina. Quien nunca ha escuchado estas voces no es poeta. (Reyes, 1929: 17; el énfasis no está en el original) 
Poco antes de llegar a Buenos Aires, Reyes ya había advertido a Amado Alonso sobre los "falsos estilos arcaizantes" que detectaba en un poema de Baldomero Fernández Moreno (Venier, 2008: 3). En el ensayo publicado en Libra, retoma esta prevención ante lo arcaico y presenta, en contraposición, esta tesis alternativa sobre la cultura popular: la potencialidad moderna de los tradicionales juegos del lenguaje. En un clima de abierta controversia sobre los alcances de lo popular y sobre las estrategias más adecuadas para su representación estética y articulación política, Reyes analiza con insistencia las posibilidades artísticas de estos usos recientemente catalogados por la filología y rastrea su productividad literaria a partir de una genealogía tan arbitraria como ecléctica que, en consonancia con las propuestas vanguardistas, va desde los juegos orales infantiles hasta los últimos experimentos poéticos del modernism. En una última versión de su ensayo, incorporada en el volumen La experiencia literaria de 1941, consigna el catálogo completo de las propuestas estéticas que exhiben la discontinuidad lógica del lenguaje:

Se empieza por la embriaguez de los sonsonetes pueriles, tipo BurchielloRabelais; se pasa por el circunloquio preciosista, lengua de iniciados, gongorismo, conceptismo, marinismo, eufuismo; por el que se llamó en el siglo XVIII 'estilo creado'; se llega a la cristalización conceptual de Valéry, a la caricatura fonética de Fargue, donde parecen realizarse valientemente muchas tentaciones del lenguaje, o a la preocupación de Joyce por escapar a la abstracción simbólica y devolver a las palabras la fluidez del espíritu. Dice el manifiesto de Transition: ${ }^{24}$ 'Permitir que la discontinuidad del lenguaje traduzca la continuidad del pensamiento'. (Reyes, 1941: 224)

Este engarce de autores y de prácticas discursivas de ineludible cariz moderno ofrece un muestrario zigzagueante de núcleos literarios que, lejos de "los falsos estilos arcaizantes", se ponderan "por su mayor emancipación de los moldes lógicos y lingüísticos” (Reyes, 1941: 201), es decir, por su materialidad sonora y su valencia en la cadena de significantes. Jorge Monteleone ha señalado, incluso, que "el núcleo estilístico de la prosa de Reyes, como aspiración, como deber-ser, radicaría en provocar un residuo de oralidad y un efecto de conversación” (1999: 103). Este acento sobre la oralidad prelógica y sobre la "desviación” dialectal habría permitido procesar simbólicamente los excesos verbales gongorinos, los silencios mallarmeanos y las “travesuras lingüísticas” de Brull y los jóvenes vanguardistas.

De este modo, la noción de ruido parece haber cumplido una función crucial en su teoría poética ya que la conceptualización de lo popular, y de sus novísimas modulaciones urbanas, señala un punto de inflexión en el proceso de lectura de la

${ }^{24}$ Se refiere a la revista Transition que Eugene Jolas logró publicar desde París a partir de 1927 y que reunió notables contribuciones de James Joyce, Franz Kafka, entre otros. 
tradición hispana y, a la vez, afirma sus ideas sobre el papel de los intelectuales en la configuración diferencial de un pensamiento americanista. Es la percepción del sonido dialectal, la escucha del matiz tonal, lo que dispara la posibilidad de imaginar una sensibilidad americana y su estadía en el Sur la que permite complejizar las hipótesis iniciales y transformar los ruidos del "populacho" en una teoría sobre el ruido poético.

"No todo espacio es propenso al sobresalto acústico", señala Julio Ramos (2010: 53) a propósito de las percepciones auditivas de Walter Benjamin en la porosidad de las fronteras del capitalismo, pero sobre todo en el frenesí urbano de las ciudades de la periferia. En una de esas ciudades, en efecto, en Buenos Aires, y en un período de enorme conflictividad política y crecientes debates en torno de las culturas nacionales, Reyes habría encontrado la posibilidad de revisar su categorización de lo popular. De esa época datan también las entradas de su Diario en las que registra la preocupación por las transmisiones telegráficas de la voz, un avance reciente que lo contó entre los impulsores más tenaces. El 6 de diciembre de 1928 escribe, por ejemplo, "Comienza la conversación para hacer pruebas de Radio México-Buenos Aires” (Reyes, 1969: 237); el 26 de enero siguiente: “Comienzo a ocuparme de mis comunicaciones radiotelefónicas con México, y concibo un puesto emisor [...] para uso de la Embajada" (Reyes, 1969: 250); el 1 de febrero: "realizamos la prueba de radiotelegrafía entre Chapultepec y la Transradio, directamente, con el mayor éxito" (Reyes 1969: 254), y continúa. Es evidente que las innovaciones tecnológicas lo atraían tanto o más que los sonidos de los giros populares que, por esa misma época, estudiaba a propósito de su figuración literaria: dos polos aparentes de una misma preocupación estética por la alternancia entre ruido y silencio.

\section{Las niñas que nacieron peinadas}

El largo ensayo sobre la función poética de los ruidos - ese "raro dialecto" (Reyes 2003: 7)- culmina en la escena de recitado de la niña que se comentó al inicio de este artículo. En su descripción se advierte un énfasis particular de Reyes sobre el efecto seductor de estas emisiones orales infantiles ("gorjeos”, "canción de pájaro" ${ }^{25}$ ) en un auditorio acostumbrado a la consabida circunspección de los versos de la tradición hispana:

...creedme que el efecto era irresistible cuando, en aquella sala donde solían oírse versos españoles del Romanticismo y de la Restauración, comparecía la mayorcita y, aceptando la broma con esa inmensa sencillez que tienen los niños,

${ }^{25}$ Felipe Cussen (2009) ha rastreado el fecundo uso de estas imágenes sobre la sonoridad de los pájaros en distintos poetas de tradiciones culturales a veces contrapuestas. 
gorjeaba, dulce y llena de despejo -en vez de la fábula manida o los machacones versos de párvulos — esta verdadera canción de pájaro:

Filiflama alabe cundre

Ala olalúnea alífera

Alveolea jitanjáfora

Liris salumba salífera (Reyes 2003: 21-2) ${ }^{26}$

Sin embargo, la seducción de los sonidos gorjeados por la niña no parece haber tenido efecto inmediato ya que la recepción inicial del texto osciló entre el desconcierto y las acusaciones de frivolidad y cursilería ${ }^{27}$. En la década de 1980, en cambio, más de cincuenta años después, alcanzó una insospechada resignificación en el ensayo de Arturo Carrera sobre la escritura de Mirta Dermisache, "Tejidos esponjosos”. Como se dijo al inicio de este artículo, el poeta ubica allí las hipótesis de Reyes sobre el ruido poético en una de las puntas de un "arco iris caligráfico" que, a partir de la poética sonora y visual de Stéphane Mallarmé, habría refractado “las esperanzas 'modernísimas' de la futura poesía argentina” (Carrera, 1981: 29). El poeta renueva, así, la funcionalidad estética de un episodio cuasi olvidado para entonces, la jitanjáfora, y explora en él las valencias necesarias para la innovación lingüística del presente. En su tesis, la antigua jitanjáfora aporta elementos para intervenir en la articulación secular entre ruido, diferencia dialectal y poesía: “¿Por qué no podían atacar, estos 'falsos’ poetas, la mimiduplicación de otros 'ruidos' o la mimicación de un idiolecto bárbaro?” (Carrera, 1981: 30) ${ }^{28}$, ironiza. Pocas líneas después, explica la validación del juego verbal ideado por Reyes:

...en esta anécdota desplegada con tantos detalles por A. R., se me ocurre que hay una tensión y una compacidad de 'mitología' adaptable a la historia 'coherente' de la literatura.

De estas irresponsables jitanjáforas se puede pasar fácilmente [...] al texto: a un regodeo fónico fundante para nuestra escritura ¿Girondo? (Carrera 1981: 30)

Esta entronización de la escena "mitológica” de recitado infantil en un lugar preponderante de la historia de la literatura argentina se vincula con intereses temáticos y retóricos de Carrera en torno de la infancia (Fernández, 2008) no

${ }^{26}$ En la versión final de 1941, se mantiene la anécdota pero se agregan otros datos contextuales, como la ubicación de la escena en la casa del suegro de Brull: "el doctor Baralt” (Reyes, 1941: 197).

${ }^{27}$ Véanse los comentarios, reseñas y cartas recopiladas por Rose Corral al final de la edición facsimilar de la revista Libra (Reyes, 2003: 183-222).

${ }^{28}$ En las ediciones posteriores, se lee: “¿por qué no podían atacar, estas ‘niñas’ poetas, mimicriplicación de zumbidos salvajes o la imitación vertiginosa de los ideolectos bárbaros? (Carrera, [1992] 1994: 64). 
abordados aquí para evitar digresiones, pero también con una propuesta de reorganización de una tradición literaria que, en gran medida, había soslayado y omitido, hasta la década del ochenta al menos, el "regodeo fónico fundante" de la escritura, tanto en su versión barroca como en otras modulaciones experimentales (Prieto, 2009; Porrúa, 2003 y 2007). La “irresponsabilidad” verbal de las viejas jitanjáforas de Alfonso Reyes ofrece, entonces, la posibilidad de explorar el nuevo lenguaje literario y de diseñar genealogías escriturarias en donde ubicar, entre otros, a Oliverio Girondo ${ }^{29}$.

\section{Conclusiones}

Un acendrado interés por discernir las posibilidades estéticas de lo popular renovó, en las últimas décadas, el análisis de las estrategias discursivas del Barroco y resignificó la experimentación poética centrada en la opacidad de la lengua. En este proceso, las especulaciones teóricas de Alfonso Reyes en torno del valor poético de los sonidos inarticulados que provienen de los usos populares de la lengua $\mathrm{y}$ sus modulaciones dialectales adquirieron renovada actualidad y permitieron revisar un entramado genealógico que exhibe un itinerario de múltiples refracciones sobre la actualidad estética de las prácticas populares. En esta compleja trama, las hipótesis de Reyes sobre el valor innovador que caracteriza a las prácticas lingüísticas del vulgo así como su incorporación posterior en una teoría sobre la experiencia literaria moderna aparecen como uno de los núcleos más productivos para pensar la articulación de lo popular en la poesía contemporánea. Y así fue, en consecuencia, como los lectores argentinos de los ochenta fueron convocados a percibir la pertinencia literaria de los olvidados "chillidos pentatónicos" de unas Meninas redivivas.

La actualización de esta escena de recitado y sus correlatos en la poesía neobarroca ponen de manifiesto, en primer lugar, la importancia de las formulaciones teóricas de Alfonso Reyes sobre las articulaciones entre cultura popular y cultura letrada y la innegable actualidad de sus postulados; en segundo lugar, alertan sobre la necesidad de repensar el lugar asignado a lo popular dentro del consabido universalismo humanista de Reyes, ya que podría haber ocupado un lugar más relevante que el reconocido en la mayoría de los estudios críticos; por último, incitan a traspasar las fronteras de las literaturas nacionales para explorar la trama inter y transdiscursiva que ha configurado algunas de sus tendencias más persistentes y complejas.

${ }^{29}$ La itálica alude a los adjetivos que integran el título de la revista. 


\section{BIBLIOGRAFÍA}

ANTELO, Raúl.

2006 María con Marcel. Duchamp en los trópicos. Buenos Aires: Siglo XXI.

ARMUS, Diego (comp.).

1990 Mundo urbano y cultura popular. Estudios de historia social argentina. Buenos Aires: Sudamericana.

BORGES, Jorge Luis.

2001 Textos recobrados 1919-1929. Bogotá: Emecé.

CARRERA, Arturo.

1981 “Tejidos esponjosos”, en Xul signo viejo y nuevo. Revista de Poesía, no 3, diciembre de 1981, pp. 29-33.

1992 "Las niñas que nacieron peinadas". Org. de Horacio Costa. A palavra poética na América Latina. Sâo Paulo: Memorial da América Latina, pp. 60-68.

1994 "Las niñas que nacieron peinadas", en Cuadernos Hispanoamericanos, $\mathrm{n}^{\circ}$ 529-30, julio-agosto de 1994, pp. 63-70.

1999 "Las niñas que nacieron peinadas", en Oliverio Girondo, Obra completa. Ed. de Raúl Antelo. Madrid et al.: ALLCA XX, pp. 744-8.

CHIAMPI, Irlemar.

2000 Barroco y modernidad. México: Fondo de Cultura Económica.

CORRAL, Rose.

2003 "Estudio introductorio", Libra [1929]. Edición facsimilar preparada por Rose Corral. México: El Colegio de México, pp. 13-37.

CUSSEN, Felipe.

2009 "Del pajarístico al lenguaje de los pájaros", Acta literaria, n 39, 2009, pp. 91-103.

DELEUZE, Gilles.

1989 La lógica del sentido. Barcelona: Paidós [1969].

DI TULLIO, Ángela.

2009 "Meridianos, polémicas e instituciones: el lugar del idioma", en Celina Manzoni (ed), Rupturas, vol. VII, Historia crítica de la literatura argentina. Buenos Aires: Emecé, pp.569-596.

DUPIERREUX, Richard.

1929 "Les arts populaires et l'esprit international", La Coopération intellectuelle / Société des Nations. Institut international de la coopération intellectuelle, pp. 15-8. 
EGIDO, Aurora.

2009 "Entre las dos orillas", El barroco de los modernos. Despuntes y pespuntes. Valladolid: Junta de Castilla y León/Universidad de Valladolid, pp. 85-116.

FERNÁNDEZ, Nancy.

2008 Experiencia y escritura. Sobre la poesía de Arturo Carrera. Rosario: Beatriz Viterbo.

GAMIO, Manuel.

1916 Forjando patria (pro-nacionalismo). México: Porrúa.

GARCÍA, Miguel A. y Gloria B. CHICOTE.

2008 Voces de tinta: estudio preliminar y antología comentada de Folklore argentino (1905) de Robert Lehmann-Nitsche. La Plata / Berlín: Universidad Nacional de La Plata/Instituto Iberoamericano de Berlín.

GARCÍA MORALES, Alfonso.

1991 “La trayectoria poética de Mariano Brull”, Anales de Literatura Hispanoamericana, $\mathrm{n}^{\circ}$ 20, 1991, pp. 179-197.

GELADO, Viviana.

2008 Poéticas de la transgresión. Vanguardia y cultura popular en los años veinte en América Latina. Buenos Aires: Corregidor.

HOUVENAGHEL, Eugenia.

2002 “Alfonso Reyes y la polémica nacionalista de 1932”, Foro Hispánico, nº 12, 2002, pp. 45-56.

HUYSSEN, Andreas.

2006 "La dialéctica oculta: vanguardia-tecnología-cultura de masas", en Después de la gran división. Modernismo, cultura de masas, posmodernismo. Buenos Aires: Adriana Hidalgo, pp. 19-40. [1986]

JAUSS, Hans Robert.

1976 "La historia de la literatura como provocación de la ciencia literaria”, en La literatura como provocación. Barcelona: Península, pp. 133-211. [1970]

MONTELEONE, Jorge.

1999 "Voz en sombras: poesía y oralidad", Boletín del Centro de Estudios de Teoría y Crítica Literaria, nº 7, 1999, pp. 147-153.

PORRÚA, Ana.

2007 “'Cosas que se están hablando': versiones sobre el neobarroco”, Boletín del Centro de Estudios de Teoría y Crítica Literaria, $\mathrm{n}^{\circ}$ 13/14, diciembre de 2007-abril de 2008, pp. 84-94.

2003 "Una polémica a media voz: objetivistas y neobarrocos en el Diario de Poesía", Boletín del Centro de Estudios de Teoría y Crítica Literaria, no 11, diciembre de 2003, pp. 59-69. 
PRIETO, Martín.

2009 “Neobarrocos, objetivistas, epifánicos y realistas: nuevos apuntes para la historia de la nueva poesía argentina”, Vox virtual, $\mathrm{n}^{0} 23$, Julio de 2009. Edición en línea. Consultado el 10 de diciembre 2010.

RAMA, Ángel.

1983 “La señal de Jonás sobre el pueblo mexicano”, en La crítica de la cultura en América Latina. Caracas: Biblioteca Ayacucho, pp. 1965.

RAMOS, Julio.

2010 “Descarga acústica”, Papel máquina, vol. II, n 4, 2010. Edición en línea. Consultado el 10 de octubre 2010.

RANGEL GUERRA, Alfonso.

2005 “Cultura y letras nacionales en Alfonso Reyes: polémicas”, Casa de las Américas, $\mathrm{n}^{\circ}$ 240, julio-septiembre de 2005, pp. 20-32.

REYES, Alfonso.

1909 "Sobre el procedimiento ideológico de Stéphane Mallarmé”, en Obras completas. México: Fondo de Cultura Económica, 1955, vol. I, pp. 143-164.

1911 “Sobre la estética de Góngora”, en Obras completas. México, Fondo de Cultura Económica: 1955, vol. 1, pp. 61-85.

1912 “Los desaparecidos”, en Obras completas. México: Fondo de Cultura Económica, 1963, vol. 3, pp. 243-248.

1918 “Gracián y la guerra”, en Obras completas. México: Fondo de Cultura Económica, 1956, vol. 3, pp. 458-463.

1921 “De la lengua vulgar”, en Obras completas. México: Fondo de Cultura Económica, 1963, vol. 3, pp. 141-150.

1924 "Psicología dialectal”, en Obras completas. México: Fondo de Cultura Económica, 1956, vol. 2, pp. 339-341

1941 “Las jitanjáforas”, Obras completas. México: Fondo de Cultura Económica, 1962. vol. 14, pp. 190-230.

1969 Diario, 1911-1930. Guanajuato: Universidad de Guanajuato.

2003 “Las jitanjáforas”. Libra [1929]. Edición facisimilar preparada por Rose Corral. México: El Colegio de México, pp. 5-22.

ROBLEDO RINCÓN, Eduardo (coord.).

1998 Alfonso Reyes en Argentina. Buenos Aires: Eudeba/Embajada de México.

RUSSOLO, Luigi.

1916 L'Arte dei Rumori. Milano: Edizione Futuriste di Poesia. SÁNCHEZ PRADO, Ignacio.

2009 "Renovar a Reyes: cuatro intervenciones contracanónicas", Armas y letras, nº 66-67, 2009, pp. 8-18. 
SARDUY, Severo.

2000 “Sobre el castellano en América”, en Antología. México: Fondo de Cultura Económica, pp. 174-80.

SARLO, Beatriz.

1992 “La radio, el cine, la televisión: comunicación a distancia”, en $L a$ imaginación técnica. Sueños modernos de la cultura argentina. Buenos Aires: Nueva Visión, pp. 109-34.

SCHWARTZ, Jorge.

2002 “Los lenguajes imaginados”. Las vanguardias latinoamericanas.

Textos programáticos y críticos. México: Fondo de Cultura Económica, pp. 55-94.

VENIER, Marthe (ed.).

2008 Crónica parcial. Cartas de Alfonso Reyes y Amado Alonso. México: El Colegio de México. 